\title{
Simulation of Energy Conversion Efficiency of a Solar Cell with Gratings
}

\author{
Sung Chul Kim ${ }^{1 *}$ and Insoo Sohn ${ }^{2}$ \\ ${ }^{1}$ Department of Information and Communication Engineering, Myongji University, Yongin 449-728, Korea \\ ${ }^{2}$ Division of Electronics \& Electrical Engineering, Dongguk University-Seoul, Seoul 100-855, Korea
}

(Received May 26, 2010 : revised June 3, 2010 : accepted June 3, 2010)

\begin{abstract}
In this work, a numerical analysis of a CIGS $\left(\mathrm{CuIn}_{1-\mathrm{x}} \mathrm{Ga}_{x} \mathrm{Se}_{2}\right)$ solar cell with a rectangular grating on the electrode is presented. The effects of the grating on the energy conversion efficiency are calculated using the RCWA (rigorous coupled wave analysis) method. In conventional CIGS solar cells, the thickness of the light absorption layer (CIGS) is $2 \mu \mathrm{m}$, at which the incident light is almost absorbed. By adopting a grating on the electrode and using a less than $1 \mu \mathrm{m}$ CIGS layer, we obtained a higher efficiency compared to the conventional solar cells.
\end{abstract}

Keywords : CIGS, Solar cell, RCWA, Grating

OCIS codes : (230.0230) Optical devices; (230.1950) Diffraction gratings; (230.4170) Multilayers; (130.5990) Semiconductors

\section{INTRODUCTION}

Recently, solar cells have gained significant interest due to their environmentally friendly technology. There are several semiconductor materials for converting light power into electricity such as c-Si (crystalline $\mathrm{Si}$ ), GaAs, CdTe, CIGS(CuInGaSe), etc. c-Si has been the most popular material for solar cells because its high internal quantum efficiency due to its crystalline structure gives the highest energy conversion efficiency achieved to date. However, by its indirect bandgap, $\mathrm{Si}$ has a poor light absorption efficiency, making it necessary to make the thickness of $\mathrm{Si}$ to be on the order of several hundred micrometers. This has been a roadblock preventing $\mathrm{c}-\mathrm{Si}$ solar cell use in office buildings and as a home electric power source due to its high manufacturing cost. Reducing the thickness of the thin film solar cell is a promising technology for saving on expensive semiconductor materials and decreasing the process time. Among various thin film technologies, amorphous $\mathrm{Si}$ (a-Si) is a strong candidate for replacing $\mathrm{c}-\mathrm{Si}$ because there are tremendous technical achievements in the LCD (liquid crystal display) technology due to factors such as a very low cost, mass production, and large scale processing of a-Si as an active device. But, a-Si has light absorption characteristics similar to those of c-Si. Besides, a-Si has very low internal quantum efficiency due to its amorphous structure. To enhance the absorption of the light, several light trapping methods such as nano-scale structure, gratings, and surface texturing have been developed [1-3]. Even if the light trapping methods show successful improvements in the energy efficiency of an a-Si solar cell, the efficiency is less than $10 \%$ at the research level, and it is about $4-5 \%$ at the production level.

For CIGS solar cells, an active layer thickness below 2 $\mu \mathrm{m}$ is of great interest, and due to its high optical absorbing property over hundreds times more than $\mathrm{Si}$, CIGS is a promising candidate for the next generation thin film solar cell [4-7]. In this paper, a grating structure is proposed to reduce the active layer thickness to a level less than $1 \mu \mathrm{m}$ and we show the enhanced light absorbing characteristics compared to the conventional structure. RCWA algorithm [8] is used to calculate the amount of the absorbed, reflected and transmitted light at the solar cell. Finally, the energy conversion efficiency is calculated by using the well-established characteristic equation for CIGS material [7].

\section{STRUCTURE OF CIGS SOLAR CELL}

The common structure of CIGS solar cell [4] is depicted

\footnotetext{
*Corresponding author: schkim@mju.ac.kr

Color versions of one or more of the figures in this paper are available online.
} 


\begin{tabular}{|c|}
\hline Glass, $\mathrm{n}=1.511$ \\
\hline $\begin{array}{c}\text { Transparent conducting layer (TCO) } \\
\mathrm{ZnOAl}\end{array}$ \\
\hline $\mathrm{ZnS}$ \\
Active layer (CIGS) \\
\hline Conductor (Mo) \\
\hline Glass, $\mathrm{n}=1.511$ \\
\hline
\end{tabular}

(a)

\begin{tabular}{|c|}
\hline Glass, $\mathrm{n}=1.511$ \\
\hline Transparent conducting layer ( $\mathrm{ZnOAl})$ \\
\hline Conductor (Mo) \\
\hline Glass, $\mathrm{n}=1.511$ \\
\hline
\end{tabular}

(b)

FIG. 1. (a) Conventional layer structure of CIGS solar cell, and (b) proposed structures with rectangular gratings in the TCO, A -Period of the grating, D - depth of the grating.

\section{in Fig. 1 (a).}

The refractive index and absorption coefficient of the CIGS according to wavelength are obtained from Ref [5], and the mole fraction $\mathrm{x}$ in $\mathrm{CuIn}_{1-\mathrm{x}} \mathrm{Ga}_{\mathrm{x}} \mathrm{Se}_{2}$ is set to 0.3 , which is the general case in most CIGS solar cells. For conventional CIGS solar cells, the thickness and refractive index for each layer are listed in table 1.

As shown in fig. 1(a), the incident lights travel into the light absorbing layer (CIGS) without any loss. Inside CIGS layer, the light is absorbed and changed into electron-hole pairs, and the electron goes up to the upper conductor layer (TCO), at the same time, the hole goes down to the Mo layer. By these processes, the light energy is changed into electrical power. The light from the sun consists of nearly parallel rays with random polarizations. When the light enters the solar cell normal to the surface, then the travel length of the light in the CIGS layer is only $2 \mu \mathrm{m}$. If the light can be diffracted at angles with respect to the layer surface, the travel length of the light in the CIGS will be increased over several micro meters, and hence, more light is absorbed with less thickness of CIGS, for example, $1 \mu \mathrm{m}$. This can be achieved in the proposed
TABLE 1. Material parameters for CIGS solar cell

\begin{tabular}{c|c|c}
\hline \hline Material & Refractive index & Thickness \\
\hline Glass & 1.511 & $500 \mathrm{~nm}$ \\
\hline $\mathrm{ZnOAl}$ & 1.95 & $1000 \mathrm{~nm}$ \\
\hline $\mathrm{ZnS}$ & 2.27 & $100 \mathrm{~nm}$ \\
\hline CIGS & See Ref $[5]$ & $2 \mathrm{~mm}$ \\
\hline Mo & 2.0 & $1000 \mathrm{~nm}$ \\
\hline
\end{tabular}

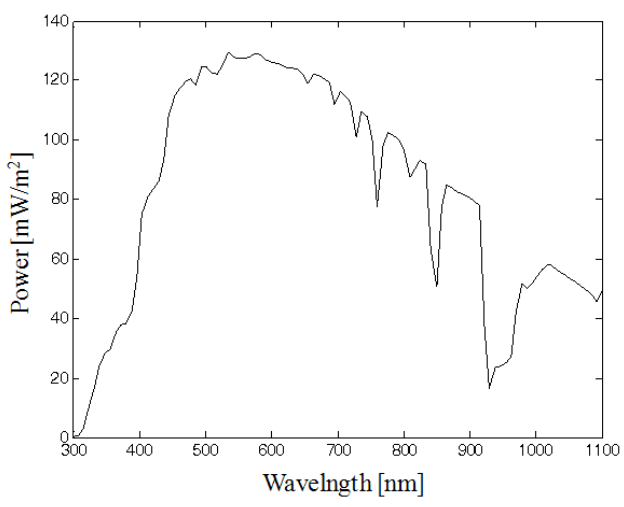

(a)

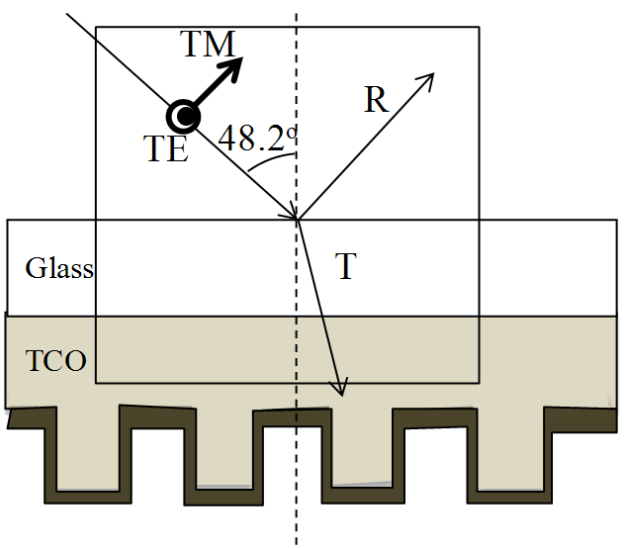

(b)

FIG. 2. (a) The power spectrum of AM 1.5 and (b) two polarizations of the incident light, TE-transverse electric, $\mathrm{TM}$ - transverse magnetic, R- reflection, $\mathrm{T}$ - transmission.

structure in fig. 1 (b). The grating in the $\mathrm{TCO}$ and $\mathrm{ZnS}$ diffracts makes the incident light into the active (light absorbing) layer. The optimum period and depth of the grating can be determined by finding through simulation the best energy conversion efficiency considering the limit of the capable semiconductor fabrication process. The equation for energy conversion efficiency of the CIGS layer which converts the incident light into electrical energy is well explained in ref [7].

In the field of solar cells, the light from the Sun is generally modeled by the Air Mass model (AM) which considers the atmosphere of the Earth. Especially, in the mid-latitudes, AM 1.5 is used as a standard sunlight model 
as shown in fig. 2 (a). In AM 1.5, the wavelength covers at least from $300 \mathrm{~nm}$ to $1100 \mathrm{~nm}$, and the light is incident upon the surface of the Earth (or a solar cell installed parallel with the Earth) with an angle of $48.2^{\circ}$. In fig. 2 (b), the light is divided into two orthogonal polarized, TE and TM modes with 50:50 power ratios due to the random polarization nature of the light through the atmosphere from the Sun.

\section{NUMERICAL RESULTS}

In the simulation presented in this paper, the internal quantum efficiency of CIGS material is set to $100 \%$ because only the effect of the grating on the CIGS thickness reduction and the energy efficiency are considered. The 3-dimensional RCWA algorithm is used and computed by the parallel computing method built in MATLAB which is a well-known engineering programming software. In RCWA, the accuracy is determined by the Fourier orders used in the calculation. Fig. 3 shows the absorption rate when F-order (Fourier order) varies from 1 to 18 . The period and depth of the grating in this case are $1100 \mathrm{~nm}$ and $400 \mathrm{~nm}$, respectively. The absorption rate is nearly unchanged when F-order is over 10. Therefore, in the simulation, F-order 13 is used.

Fig. 4 shows the simulation results for the solar cells with the grating and without the grating. The period and depth of the grating are the same as those of fig. 3. In the simulation, to separate the effect of the thickness of the active layer, the absorption coefficient of the CIGS material in the portion of the grating, which is inside the ' $\mathrm{D}$ ' portion in fig. 1(b), is neglected. Therefore, the CIGS in the ' $\mathrm{D}$ ' portion is not the active material, and only is considered as a dielectric material. If CIGS in the ' $D$ ' portion is considered as an active material, the efficiencies of the solar cells with grating will be higher than those in fig. 4 .

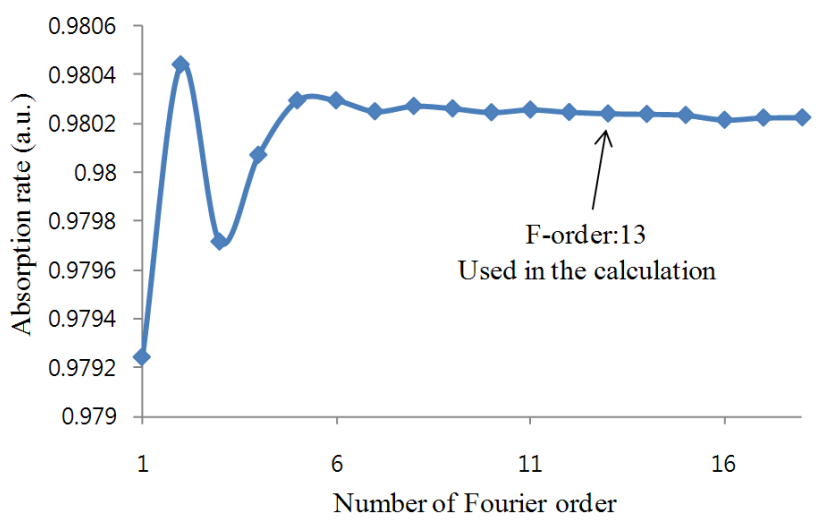

FIG. 3. Absorption rate with respect to Fourier order in the 3-dimensional RCWA algorithm; grating' period $110 \mathrm{~nm}$, depth - 400nm.

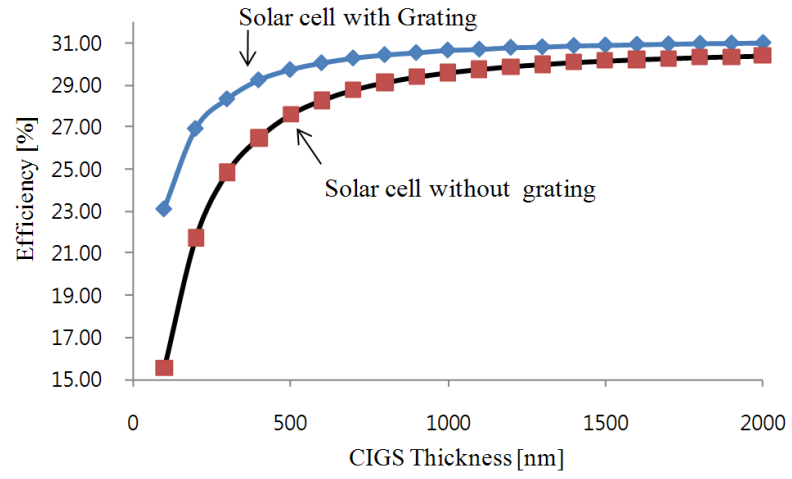

FIG. 4. Simulation results for solar cells with the grating and without the grating; grating's period $-1100 \mathrm{~nm}$, depth - $400 \mathrm{~nm}$.

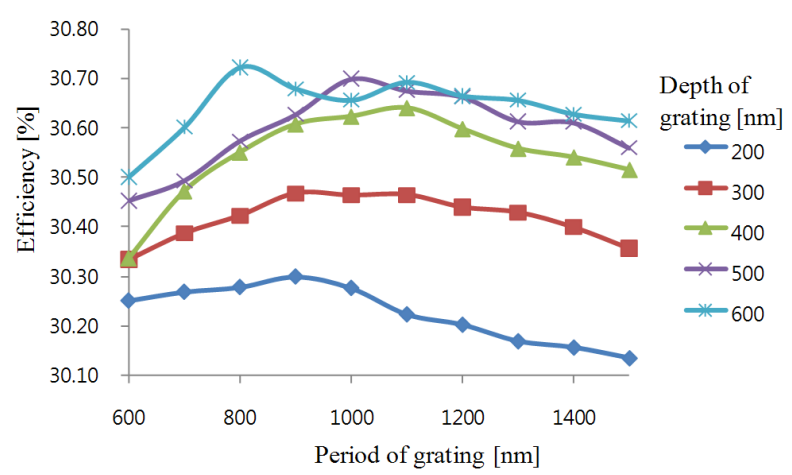

FIG. 5. Energy conversion efficiency when the period of the grating is changed with the variation of the period and the depth.

In fig. 4, the effect of the grating on the efficiency enhancement is verified. The thinner CIGS solar cell shows a great improvement in efficiency. The efficiency of CIGS with thickness of $2 \mu \mathrm{m}$ with planar structure is $30.40 \%$, whereas, that of the grating structure of CIGS with $1 \mu \mathrm{m}$ thickness is $30.64 \%$. The energy conversion efficiencies for the various grating periods and depths are shown in Fig. 5. The best energy conversion efficiency is $30.72 \%$ when the period and depth are $800 \mathrm{~nm}$ and $600 \mathrm{~nm}$, respectively. Without the grating, the efficiency is 29.61 when the CIGS thickness is $1 \mu \mathrm{m}$. With the CIGS thickness of $2 \mu \mathrm{m}$, the efficiency is $30.40 \%$ which is still $0.32 \%$ lower value compared to the solar cell with the grating structure. According to the simulation results, we can conclude that the CIGS solar cell with the grating can have very thin active layer less than $1 \mu \mathrm{m}$, and hence, it is possible to reduce the amount of expensive semiconductor materials and the process time.

\section{CONCLUSION}

In this paper, the effect of the grating on the energy 
efficiency of the CIGS solar cell is verified by the simulation of a well-known RCWA algorithm. By adopting the grating structure inside the solar cell, the thickness of the active layer, which is made of very expensive semiconductor materials, can be made to be less than $1 \mu \mathrm{m}$ without any loss of energy conversion efficiency.

\section{REFERENCES}

1. L. Zeng, Y. Yi, C. Hong, J. Liu, N. Feng, X. Duan, and L. C. Kimerling, "Efficiency enhancement in Si solar cells by textured photonic crystal back reflector," Appl. Phys. Lett. 89, 111111-1 11111-3 (2006).

2. C. Haase and H. Stiebig, "Thin-film silicon solar cells with efficient periodic light trapping texture," Appl. Phys. Lett. 91, 061116-1 061116-3 (2007).

3. P. Bermel, C. Luo, L. Zeng, L. C. Kimerling, and J. D. Joannopoulos, "Improving thin-film crystalline silicon solar cell efficiencies with photonic crystals," Opt. Exp. 15, 1698617000 (2007).
4. J. Krc, G. Cernivec, A. Campa, J. Malmstrom, M. Edoff, F. Smole, and M. Topic, "Optical and electrical modeling of $\mathrm{Cu}(\mathrm{In}, \mathrm{Ga}) \mathrm{Se}_{2}$ solar cells," Optical and Quantum Electronics, 38, 1115-1123 (2006).

5. P. D. Paulson, R. W. Birkmire, and W. N. Shafarman, "Optical characterization of $\mathrm{CuIn}_{1-\mathrm{x}} \mathrm{Ga}_{\mathrm{x}} \mathrm{Se}_{2}$ alloy thin films by spectroscopic ellipsometry,” J. Appl. Phys. 94, 879-888 (2003).

6. K. Orgassa, U. Rau, H. W. Schock, and I. U. Werner, "Optical constants of $\mathrm{Cu}(\mathrm{In}, \mathrm{Ga}) \mathrm{Se}_{2}$ thin films form normal incidence transmittance and reflectance," in Proc. $3^{\text {rd }}$ World Conference on Photovoltaic Energy Conversio (Osaka, Japan, 2003), pp. 372-375.

7. A. Yamada, K. Matsubara, K. Sakurai, S. Ishizuka, H. Tampo, H. Shibata, T. Baba, Y. Kimura, S. Nakamura, H. Nakanishi, and S. Niki, "Built-in potential and open circuit voltage of heterojunction $\mathrm{CuIn}_{1-\mathrm{x}} \mathrm{Ga}_{\mathrm{x}} \mathrm{Se}_{2}$ solar cells," in Proc. Mater. Res. Soc. Symp. (San Francisco, USA, 2005), vol. 865, pp. F5.19.1-F.5.19.6.

8. H. Kim and B. Lee, "Pseudo-Fourier modal analysis of two-dimensional arbitrarily shaped grating structures," J. Opt. Soc. Am. A 25, 40-54 (2008). 